\title{
Education and training activities in the Euratom CONFIDENCE project
}

\author{
T. Duranova ${ }^{1, *}$, N.A. Beresford ${ }^{2}$, T. Perko ${ }^{3}$ and W. Raskob ${ }^{4}$ \\ 1 VUJE-VUJE, a.s., Trnava, Slovak Republic. \\ ${ }^{2} \mathrm{CEH}$-UK Centre for Ecology \& Hydrology, Lancaster, United Kingdom. \\ 3 SCK-CEN-Belgian Nuclear Research Centre, Mol, Belgium. \\ ${ }^{4}$ KIT-Karlsruhe Institute of Technology, Eggenstein-Leopoldshafen, Germany.
}

\begin{abstract}
The education and training activities formed a key part of the CONFIDENCE project and were integrated into the research programme. The activities varied from training courses through to workshops and courses for students, integrating achievements from the CONFIDENCE project. The tasks were developed and realised in collaboration with academic departments' outwith the CONFIDENCE consortium. Educational materials as well as lectures, round table discussions and table-top exercises have been conducted at universities. In such a way we have reached the next generation of Radiation Protection specialists. Junior scientists, post-doctoral researchers and PhD. students have also been involved in CONFIDENCE's core research activities. A final dissemination meeting focused on communicating the main achievements of the project.
\end{abstract}

Keywords: education / training / dissemination / decision support / CONFIDENCE

\section{Introduction}

The CONFIDENCE project (COping with uNcertainties For Improved modelling and DEcision making in Nuclear emergenCiEs) (Raskob et al., 2020) was part of the CONCERT European Joint Project (EJP; https://concert-h2020.eu/). Education and Training (E\&T) is an essential part of dissemination and knowledge management within CONCERT. CONCERT promoted E\&T as an integral part of CONCERTfunded RTD projects, by requiring projects to include evidence that due consideration was been given to the incorporation of graduate student involvement and the offering of new or specialist technologies as topics for E\&T courses. The first call for the RTD projects under the CONCERT project included the following requirements: "Education and training is an essential part of all activities within CONCERT. Proposals shall include a plan for integration of education and training into the research programme, with a description of the proposed activities. This must also give details of collaboration or involvement with academic departments, and of intended PhD thesis work, MSc project work, teaching seminars, ad hoc courses on the topics of the proposal, etc., where possible. The plan will be assessed as an essential part of the impact statement and will be considered within the evaluation procedure".

\footnotetext{
*Corresponding author: tatiana.duranova@vuje.sk
}

The CONFIDENCE project in its E\&T section fully covered these requirements with the following objectives: "Develop training courses and educational material for professionals and students related to CONFIDENCE issues and activities and to disseminate the results in a form of a dissemination workshop and open access Journal'. Supporting people in building their own response to the consequences of a nuclear accident was studied within the PREPARE project (see Heriard-Dubreuil and Baudé, 2016). The way of how it could be realised with focus on use and communication of uncertain information was deeply studied and implemented within the E\&T part of the CONFIDENCE project.

The following tasks were defined to meet the objectives:

- Training course "Use of uncertain information by decision makers at the various levels within the decision making process and its communication";

- Workshop "Do process-based models have a role in human food chain assessments";

- The CONFIDENCE course "Communication under uncertainty: Nuclear or radiological emergencies, radiation protection and other issues important to know for your (future) occupation";

- CONFIDENCE Dissemination workshop;

- Radioprotection Journal Special Issue.

This article provides information on how these tasks have been realised. 


\section{Training course "Guidance on the use of uncertainty information by decision makers"}

The training course "Use of uncertain information by decision makers at the various levels within the decision making process and its communication" was developed, prepared and conducted at VUJE, Trnava, Slovak Republic, 13-15 May, 2019 with 25 participants from 15 countries. The objective was to present guidance and recommendations for decision making in the post release and transition phase taking into account uncertain information. An objective of the course was focused on how to interpret, use and communicate uncertainties within the decision making process. Training the trainers and facilitators of national, regional and local workshops was one of the goals.

The training course was targeted at decision makers, advisors and stakeholders who would be at various levels (national, regional, local) within the decision making process during the post release and transition phase of a nuclear/ radiological accident.

The training course covered the following topics in oral presentations:

- Decision processes in case of nuclear accidents and decision support tools;

- Meaning of different types of uncertainty;

- Uncertainties in the early phase influencing the transition phase;

- Visualization of uncertainties in model results for decision making;

- Addressing the uncertainties in urban/inhabited and agricultural area scenarios;

- Application of tools MCDA (multi-criteria decision analysis) and ABM (agent based modelling);

- Robust decision making;

- Decision-making in a post nuclear accident situation: confronting uncertainties, criteria supporting decisions and tools for their presentation;

- Uncertainties in human behaviour, cultural differences and social uncertainties as a part of the tools and approaches to support the decision making process;

- Resilience criteria for rebuilding dignified living conditions after a nuclear accident;

- Testing communication tools through consideration of uncertainties within the decision making process.

Participants actively participated in practical sessions in the form of short topical workshops using exercise scenarios and round table discussions.

Group scenario-based workshops followed-up the results in the area of development of countermeasure strategies involving stakeholders and social, ethical and communication aspects of uncertainty management of the CONFIDENCE project in the particular areas of:

- Decision making during the transition phase: establishment and optimization of remediation strategies - urban/inhabited and agricultural area;

- Stakeholder preferences and priorities concerning uncertainty management: Key features of an accident and post- accident situation, and of the challenges for local populations facing a nuclear accident:

- Suetsugi case study (Japan): Radiological situation and quality of food products;

- Tominari case study: Decontamination of elementary school in Date city (Japan).

Round table discussions at the end of each day summarised:

- Uncertainty information and how it is used by decision makers at various levels within the decision making process;

- Involvement of stakeholders in the decision making process;

- Feedback on communication and observation of exercises during the training course.

On the question "What was the knowledge gained from the training course" we received following answers:

"I learnt here about decisions tools as well as different uncertainties across different stages and multi-disciplinary aspects."

"I can go back home and use these tools and provide some feedback."

"What I would like to take home from this workshop is how I can engage food agencies in these situations of what CONFIDENCE is dealing with. The second goal is to think how we can apply this to our country context."

"I got the chance to understand what everyone is doing, got to know about different packages, and get in touch with people from different disciplines."

"It was very useful to have different points of view."

"It was very useful to see what is being done on Europe so that we can exchange information with each-other."

"The fact that some of our countries don't have NPPs, doesn't mean that we aren't related to or shouldn't be involved in emergency situations."

In the follow-up discussion we received recommendations from the participants:

- "The only thing missing here is taking into consideration the radiological aspects in addition to nuclear ones, e.g. transport accidents, fire in a hospital treating patients, terrorist attacks, etc."

- "There is a gap with expert information and how that information is sent to the public. In my opinion, we need to increase media attention to this issue. When we survey people about what they fear the most, the radiological concerns are on top. Still, people don't talk about the uncertainties as well as the efforts made to treat or reduce them."

- "The public needs to be educated regarding radiological/ nuclear aspects, dangers etc. e.g.: by school materials. This would help reduce uncertainties."

The experience and very positive feedback on the training course developed and conducted in a very interactive and dynamic way (Fig. 1 presents some snapshots) influenced the 


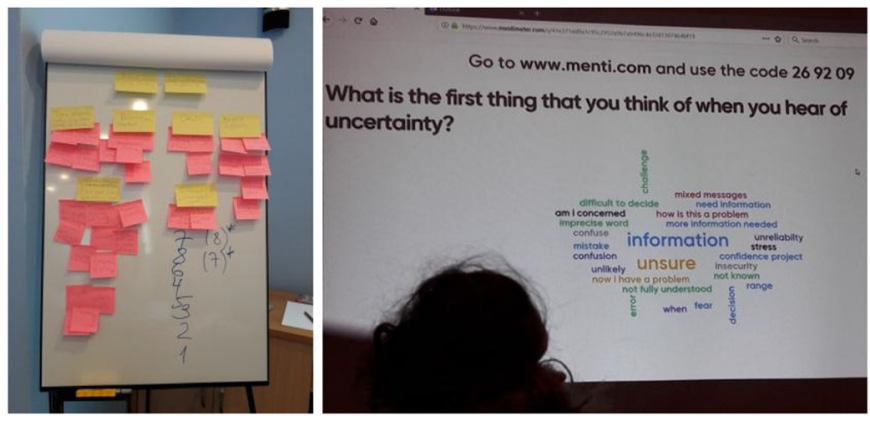

Fig. 1. Snapshots from the training course.

preparation and development of the final CONFIDENCE dissemination workshop.

\section{Workshop "Do process-based models have a role in human food chain assessments"}

The workshop "Do process-based models have a role in human food chain assessments" took place in September 9-11, 2019 in Madrid (CIEMAT) with a range of 40 stakeholders (industry, regulators, scientists and representatives from international organisations) (see Almahayni et al., 2019).

The aim of this CONFIDENCE workshop was to discuss soil plant process-based models with a range of stakeholders (industry, regulators, scientists and representatives from international organisations) to gain opinion on if stakeholders saw benefit in process-based model use and development. In part, this was motivated by the priority given to process based models by scientists (e.g. in the ALLIANCE Strategic Research Agenda, https://radioecology-exchange.org/content/strategic-re search-agenda) versus a perceived lack of uptake of previously developed process-based models by end users.

A number of presentations were given to aid discussion, including: "conventional" food chain models; an overview of process based soil plant models for Cs; application of processbased soil plant models for Cs post Fukushima in Japan; a regulators perspective of process-based models; CONFIDENCE activities on $\mathrm{Cs}$ and $\mathrm{Sr}$ process-based soil plant models.

Presentations were followed by facilitated "breakout" sessions to discuss process-based models and their use. To prompt discussion the following questions were posed:

1. What is stopping 'you' from using process-based models?

2. Do process-based models have a use in post-accident management?

3. When should process-based models be used/when are they useful?

4. Are we confident that process-based models have been sufficiently parameterised/tested?

5. Are process-based models useful in communicating information?

A number of workshop participants expressed some doubts about process-based models:
"Process-based models are too complicated requiring a considerable amount of data to implement them"

"As a consequence of their complexity process-based models are difficult to communicate to stakeholders including the public"

"Process-based models have not been sufficiently tested and hence end users are not confident in their use"

"Scientists have not 'made the case' for process based models"

"Change to an established system (i.e. modelling approach) has financial and time implications"

Other workshop participants (including regulator/ industry end users) were of the opinion that process-based models could be useful:

"Process-based models offer an approach to understand/address the high degree of variability in empirical plant soil concentration ratios and provide predictions more relevant to a given site"

"Process-based models (if not too complex) may be easier to explain to the public than a 'black box' model as they better reflect reality (e.g. a model that bases predictions on easily understandable soil parameters such as percentage clay, organic matter content an d/or soil potassium is easier to explain than a 'black box' model with ratios and rate constants)"

"Process-based models may be useful for site specific assessments of existing exposure scenarios"

"Process-based models may be useful in emergency planning (though the required data (e.g. soil properties) would be needed for sites)"

"Process-based models may help to justify and guide model simplifications"

"Take home" messages for CONFIDENCE identified at the workshop were:

- There are clearly some issues we need to address before process-based soil-to-plant transfer models become more widely accepted. For Cs, although we appear to be able to make relatively good predictions of activity concentrations in grass predictions for other crops are currently relatively poor. CONFIDENCE has made good progress in developing process-based soil-to-plant transfer models for $\mathrm{Sr}$ although these models currently can only make equilibrium predictions of $\mathrm{Sr}$ activity concentrations in crops. We acknowledge the need to validate available process-based soil-to-plant transfer models for a wider range of scenarios (soil types and crops). Once this is done, then uptake of process based models would benefit from some welldesigned training provision aimed at different stakeholders with demonstrations of the comparative predictions of process based and conventional empirical concentration ratio based models;

- When communicating process-based models to regulators and other stakeholders we need to make it clear that process-based models are not necessarily complicated and/ or resource intensive (for example in the case of $\mathrm{Sr}$, the simplest model proposed by CONFIDENCE requires only calcium concentrations in soil and plants (Almahayni et al., 2019)). End users need to have confidence in the outputs of 
models which stresses the importance of communication and of model validation and inter comparison exercises. Models should be optimised to those few key parameters that really matter (the development of models for $\mathrm{Sr}$ in CONFIDENCE is an example of such parameter optimisation/model reduction). Model complexity may change depending upon need, but it would be useful to have one modelling package from which different components could be selected. The implementation of FDMT, the "Absalom" model and a model for "hot particles" into the EGOLEGO package within CONFIDENCE is a step to meeting this recommendation (see Almahayni et al., 2019 and Brown et al., 2020 for details);

- With respect to post-accident response, the majority of workshop participants agreed that the application of process-based models would become more relevant as time progressed and when more specific questions with regard to contaminated areas needed to be answered. In the earlier stages after an accidental release, many considered that conventional models would be adequate. However, if process-based models were sufficiently validated and spatially implemented, they could also play an early role in identifying areas where food chain issues may persist into the longer term. The comment (made a number of times) that, conventional models would be sufficient in the short term but perhaps not optimal in the longer term, implies that long term predictions from conventional models should be communicated with care. It was also suggested that process-based models may be of relevance to other scenarios, and radionuclides, including long term assessments of waste disposal facilities.

\section{CONFIDENCE course "Communication under uncertainty"}

The CONFIDENCE course "Communication under uncertainty: Nuclear or radiological emergencies, radiation protection and other issues important to know for your (future) occupation" was designed to be applicable to a wide range of students and professionals, and to be adaptable according to the needs and background of the audience.

The objective of the course was to build the capabilities, trust and confidence in radiation protection issues through engagement with the young generation via a series of lectures and round table discussions at crisis management, communication and media studies faculties.

The course dealt with the challenges with communication during and after nuclear emergencies, and in particular the way in which risk and uncertainty is addressed. Lectures were split into three modules:

1. Universal module;

2. Module for journalists and use in communication/media studies;

3. Module for first responders and decision makers.

The modules can be mixed and lectures can be chosen from each of the modules, depending on the audience's needs and wishes.

The content of the modules is as follows:

Universal module
- Introduction to societal and psychological aspects of radiological/nuclear emergencies: Some case studies;

- Provision of public information during an emergency: What and how?

- Legal aspects of public information and transparency in radiological/nuclear emergencies;

- How to communicate protective measures and address uncertainties (societal, psychological, scientific, technical...);

- Decision making process in radiological/nuclear emergencies (authorities, first responders, personal decisions) structure, coordination, process and uncertainties;

- When security and safety clash: malevolent use of a radiological source;

- Ethical aspects in a radiological/nuclear emergencies response (including journalistic aspects);

- The CONFIDENCE project.

Module for journalists and communication/media studies

- Radiation, contamination and other concepts related to a radiological/nuclear emergency; (radiation, how do we measure it, natural background, legal limits, what is safe?, contamination, irradiation, routes of exposure, comparisons, effects, comparison with radon, cancer and other health effects, radiation disease, how to measure radioactivity?);

- Slip-ups in media reporting about radiological/nuclear emergencies;

- Sources of information during and after a nuclear/ radiological emergency;

- Radiation protection of a journalist or PR officer (e.g. how can a journalist or public information officer protect him/ herself against radiation);

- The role of mass media during and after radiological/ nuclear emergencies - amplification or reduction of uncertainties?

- Public information officer: Roles, rules and responsibilities in reduction of societal uncertainties.

Module for first responders and decision makers

- Engaging with affected population: pre-, during and after an emergency;

- The role of social media during and after radiological/ nuclear emergencies;

- How to clearly communicate basic radiation concepts to lay people;

- How to explain what you do, what you don't do and what the affected person can/should do;

- Communication staff as a support for decision makers;

- Typical miss-communications during an emergency management;

- Uncertainties in emergency management and how to overcome them;

- Train, exercise and drill emergency communication;

- How to reduce uncertainties in waiting rooms and decontamination areas;

- Public meeting with the affected population: Meet and respond to people's uncertainties;

- Cross-border communication: challenges and solutions;

- Visual presentation of risks and uncertainties.

The lectures were followed by table-top exercise or facilitated scenario-based workshops and round table 

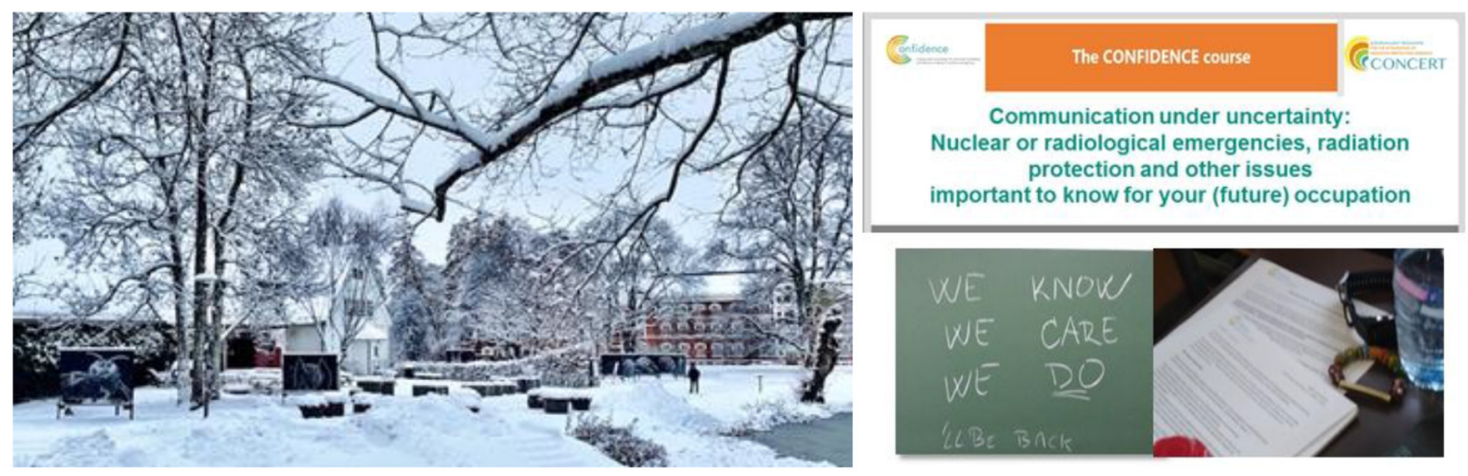

Fig. 2. Course location in Norway and snapshot from realisation.
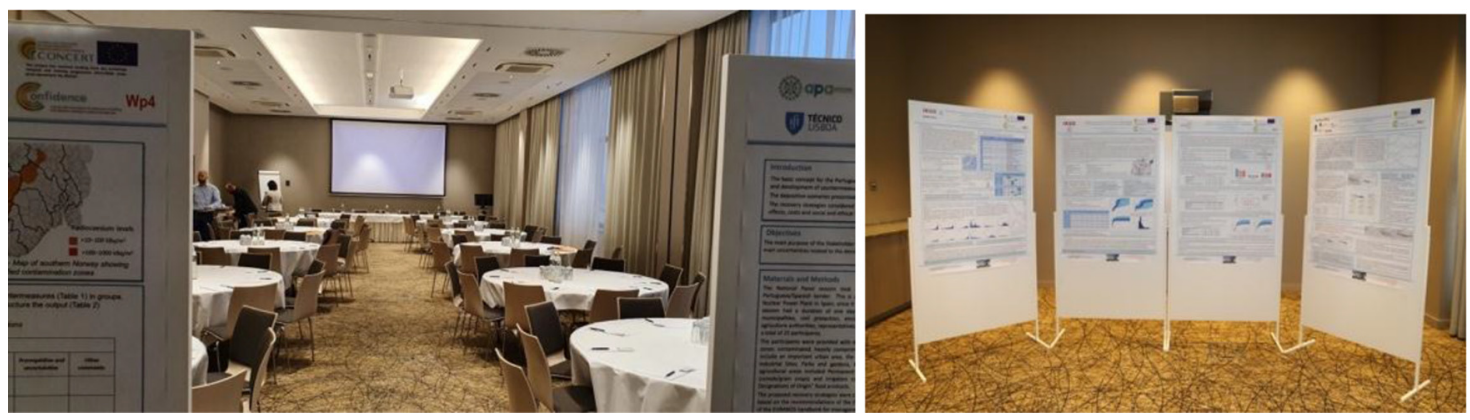

Fig. 3. Dissemination workshop facility.

discussions based on the deliverables of the CONFIDENCE project and adapted to the audience's need and wishes with focus on questions:

- How to report uncertain information in the light of accident development and taking into account the complexity of the decision making process?

- How to communicate about ionizing radiation, exposure situation and radiological risk and the process of transfer from emergency to the existing exposure situation?

- How to communicate protective measures and actions in order to improve public response, minimize uncertainties and maximize protection?

- How to report on advices and recommendations on health protection from radiological risk and on their practical implementation?

The set of courses have been prepared and conducted in Belgium (University of Antwerp, March 8, 2018), Spain (Universitat Pompeu Fabra, Barcelona, May 31, 2018 and University Polytechnica Catalonia (UPC), Barcelona, June 1, 2018), Italy (University of Milan, March 25 and April 16, 2019 and University of Milan-Bicocca, October 12, 2019), Norway (Norwegian University of Life Sciences, summer 2019) and Slovak Republic (Academy of Police Force in Bratislava, October 22 and 29, November 19, 2019) and NEA/IRPS (Nuclear Energy Agency International Radiological Protection School) held at Stockholm University in August 2018 (illustrative snapshots given in Fig. 2).

The lectures, table-top exercises and round table discussions were adapted to the needs of particular university students and level of education. There were bachelor (BSc) and master (MSc) programme students from day and external study from the listed universities as well as students from the NEA International Radiological Protection School (preparing future radiological protection leaders and other stakeholders to be involved in the emergency preparedness, response and recovery management in case of nuclear emergency).

\section{Dissemination activities}

The CONFIDENCE Dissemination Workshop took place in December 2-5, 2019 in Bratislava with 88 participants. It was designed as an interactive and dynamic meeting focusing on the main achievements of the project. Results were communicated by oral presentations, posters, scenario-based facilitated discussions, working in groups, round table discussions and panel discussions (illustrative snapshots are given in Fig. 3). Much more details on this E\&T activity are given in a separate article (Duranova et al., 2020). All materials from the CONFIDENCE dissemination workshop are available for downloading and use at the NERIS Platform web page (web site: https://eu-neris.net/home/newsletters/218-confidence-dis semination-workshop-coping-with-uncertainties-for-im proved-modelling-and-decision-making-in-nuclear-emergen cies-bratislava-slovak-republic-02-05-december-2019.html).

The 28 articles on the CONFIDENCE project form a Special Issue of the Radioprotection journal (http://www.radioprotec tion.org/) which has been published as Open Access.

A number of $\mathrm{PhD}$ students have participated in the CONFIDENCE project and have been successful in the finalisation of their Master and $\mathrm{PhD}$ degree thesis. As an example see the "Science Slam" presentation of one of our PhD students: https://bit.ly/2RvavNJ. PhD students were involved in experimental studies and modelling activities within WP3 and 
presented their results at the international conferences being a part of the research team (García-Puerta et al., 2017; GarcíaPuerta, 2018; Tomkiv et al., 2019).

\section{Discussions and conclusions}

The education and training activities have been very successful and provided opportunity to build capabilities, trust and confidence in radiation protection issues, to strengthen capabilities of researchers, scientists and all stakeholders involved in the decision making and to disseminate the CONFIDENCE project outputs to the wider community (Duranova et al., 2019).

Based on the results achieved and feedback received further research and development activities are proposed:

- Apply the training course and lectures developed to any radiological scenario, not only to nuclear (e.g. transport accidents, fire in a hospital treating patients, terrorist attacks, etc.);

- To increase media attention to uncertainty in radiological emergencies;

- Education and training of public of different ages via participation in a range of activities (education in schools, universities and "Universities of Third Age", national and international emergency preparedness and response exercises);

- Further develop and apply the training course "Use of uncertain information by decision makers at the various levels within the decision making process and its communication" based on the CONFIDENCE Dissemination workshop outcomes;

- Analyse recommendations developed for stakeholders engagement (ENGAGE Project details in Turcanu et al., 2019) and strategy development with stakeholders involved within the emergency response and recovery processes (CONFIDENCE and TERRITORIES projects details in Montero et al., 2020 and Guillevic et al., 2020) for the development of a method of education and training alongside the setting up of a new stakeholders network to facilitate the involvement of local actors in the preparedness in emergency response and recovery;

- Communication tools and messages should be developed and tested before an emergency and included in the education and training programmes of the wide range of stakeholders including public and mass media.

Acknowledgement. The work described in this paper was conducted within the CONFIDENCE project which was part of the CONCERT project. This project has received funding from the Euratom research and training programme 2014-2018 under grant agreement No. 662287.

Disclaimer (Art. $29.5 \mathrm{GA}$ ). This publication reflects only the author's view. Responsibility for the information and views expressed therein lies entirely with the authors. The European
Commission is not responsible for any use that may be made of the information it contains.

\section{References}

Almahayni T, Sweeck L, Beresford NA, Barnett CL, Lofts S, Hosseini A, Brown J, Thørring H, Guillén J. 2019. An evaluation of processbased models and their application in food chain assessments. CONCERT Deliverable D9.15. Available from https://concerth2020.eu/en/Publications.

Brown JE, Beresford NA, Hosseini A, Barnett CL. 2020. Applying process-based models to the Borssele scenario. Radioprotection 55(HS1). https://doi.org/10.1051/radiopro/2020020.

Duranova T, Raskob W, Turcanu C, Crouail P, Perko T, Beresford N. 2019. Education and training general approaches and actions of the NERIS Platform and CONFIDENCE project. In: 4th European Radiological Protection Research Week, October 14-18, 2019, Stockholm, Sweden.

Duranova T, Bedwell P, Beresford NA, Bleher M, Gering F, Geertsema G, Hamburger T, Kaiser JC, Korsakissok I, Leadbetter SJ, Montero M, Müller T, Oughton D, Perko T, Raskob W, Tomas J, Turcanu C, de Vries H, Walsh L, Woda C. 2020. CONFIDENCE dissemination meeting: Summary on the scenario based workshop. Radioprotection 55(HS1). https://doi.org/10.1051/radiopro/2020009.

García-Puerta B. 2018. Enhance the decision-making process to minimize the impact in agricultural areas derived from a nuclear accident. In: 3rd European Radiological Protection Research Week, Young scientist session, October 1-5, 2018, Rovinj, Croatia.

García-Puerta B, Trueba C, Montero M. 2017. Local factors to make risk maps, for potential nuclear accident affected farming areas, to be applied in the decision-making process. In: 4th International Conference on Radioecology and Environmental Radioactivity (ICRER), September 3-8, 2017, Berlin. ISBN: 978-2-9545237-7-4.

Guillevic J, et al. 2020. Guidance for management/post-accident. CONCERT Deliverable D9.71. Available from https://concerth2020.eu/en/Publications and https://territories.eu/publications.

Heriard-Dubreuil G, Baudé S. 2016. Supporting people building their own response to the consequences of a nuclear accident: complexity management, trust and Aarhus Convention. Radioprotection 51(HS2): S153-S154.

Montero M, Durand V, Maitre M, Nunes P, Sala R, Crouail P, Capucho M, Paiva I, Duranova T. 2020. Guidelines and recommendations for decision making during the transition phase. Radioprotection 55 (HS1). https://doi.org/10.1051/radiopro/2020022.

Raskob W, Beresford NA, Duranova T, Korsakissok I, Mathieu A, Montero M, Müller T, Turcanu C, Woda C. 2020. CONFIDENCE: project description and main results. Radioprotection 55(HS1). https://doi.org/10.1051/radiopro/2020008.

Tomkiv Y, Garcia-Puerta B, Meskens G, Müller T, Raskob W, Oughton DH. 2019. Communicating uncertainty within decisionmaking. In: 4th European Radiological Protection Research Week, October 14-18, 2019, Stockholm, Sweden.

Turcanu C, Abelshausen B, Geysmans R, Van Oudheusden M, Meskens G, Schieber C, Schneider T, Zeleznik N, Pölzl-Viol C. 2019. Final report of the ENGAGE project. CONCERT Deliverable D9.94. Available from https://www.concert-h2020. eu/en/Publications.

Cite this article as: Duranova T, Beresford NA, Perko T, Raskob W. 2020. Education and training activities in the Euratom CONFIDENCE project. Radioprotection 55(HS1): S45-S50 